\title{
Formação docente: desafios para a Pedagogia Universitária
}

Teacher training: challenges for University Pedagogy

Formation des enseignants: défis pour la pédagogie universitaire

Darlene Silva dos Santos ${ }^{1}$

Universidade Federal do Piauí

Geovana Ferreira Melo

Universidade Federal de Uberlândia

Resumo: O presente artigo tem como objetivos aprofundar reflexões teóricas sobre a necessidade de formação docente sistematizada e cientificamente fundamentada. $\mathrm{O}$ questionamento que orientou a investigação circunscreve-se à possibilidade de que o conhecimento pedagógico, considerado um dos eixos estruturantes da docência, articulado ao domínio de conteúdos da área específica de atuação docente, possa contribuir para o fortalecimento da prática pedagógica na universidade. Trata-se de uma pesquisa de abordagem qualitativa, por meio do estudo analítico-exploratório de contribuições teóricas sobre a temática, pautadas nos seguintes referenciais (Almeida, 2012; Melo, 2018; Pimenta e Anastasiou, 2005; Bolzan, Isaia; 2010; Cunha, 2004). A análise indica a essencialidade de construir projetos institucionais que tenham como ponto de partida as necessidades formativas dos professores em contexto e, que reconheçam na pedagogia universitária o espaço profícuo para formação e profissionalização docente.

Palavras-chave: Formação docente. Docência universitária. Pedagogia universitária. Profissionalização docente.

Abstract: The present article aims to deepen theoretical reflections about the need for systematized and scientifically based teacher training. The question that guided the investigation is limited to the possibility that pedagogical knowledge, considered one of the structuring axes of teaching, articulated to the content domain of the specific area of teaching activity, can contribute to the strengthening of the pedagogical practice in the university. It is a qualitative research, through an analytical-exploratory study of theoretical contributions on the theme, based on the following references (Almeida, 2012; Melo, 2018; Pimenta and Anastasiou, 2005; Bolzan, Isaia; 2010; Cunha, 2004). The analysis indicates the essentiality of constructing institutional projects that have as their starting point the training needs of the teachers in context and that recognize in the university pedagogy the space for professional training and professionalism.

Keywords: Teacher training. University teaching. University pedagogy. Teacher professionalization.

\footnotetext{
${ }^{1}$ Doutoranda em Educação pela Universidade Federal de Uberlândia (UFU). Professora da Universidade Federal do Piauí (UFPI/CMRV). E-mail: darlenesantospi@gmail.com

${ }^{2}$ Doutora em Educação pela Universidade Federal (UFU). Professora Associada da Universidade Federal de Uberlândia. Coordenadora do GEPDEBS - Grupo de Estudos e Pesquisas em Docência na Educação Básica e Superior. E-mail: geovana.melo@gmail.com.
} 
Résumé: Cet article vise à approfondir les réflexions théoriques sur la nécessité d'une formation systématique des enseignants et scientifiquement fondé. La question qui a guidé la recherche, il se limite à la possibilité que les connaissances pédagogiques, l'un des grands principes de l'enseignement, articulée à la zone de contenu de la zone spécifique de la performance des enseignants, peut contribuer au renforcement de la pratique de l'enseignement à l'université. Ceci est une recherche qualitative, par l'étude analytiqueexploratoire des contributions théoriques sur le sujet, guidées par les références suivantes (Almeida, 2012, Melo, 2018, Pimenta et Anastasiou, 2005; Bolzan, Isaia, 2010; Cunha, 2004). L'analyse indique les projets de construction d'immeubles institutionnels essentiels qui ont leur point de départ les besoins de formation des enseignants en contexte et de reconnaître dans la pédagogie universitaire espace fécond pour la formation et la professionnalisation.

Mots-clés: Formation des enseignants. Enseignement universitaire Pédagogie universitaire. Professionnalisation des enseignants.

Recebido em: 05 de outubro de 2018 Aceito em: 10 de dezembro de 2018

\section{1- Palavras iniciais...}

A discussão em torno da docência universitária tem sido intensificada nos últimos anos, sobretudo, diante das mudanças políticas, sociais, econômicas e culturais que impactam o cenário do ensino superior. São as transformações que mobilizam processos de autocrítica e reflexões sobre o exercício da docência no contexto das universidades. Nesse contexto, os estudos de Corrêa e Ribeiro (2013) indicam o final do século XX como marco de uma intensificação, quando teve início um processo de autocrítica, principalmente, por parte de diferentes membros, integrantes das universidades sobre essa prática.

Conforme indica Scheibe, a dimensão pedagógica é recorrentemente subestimada, assim como a compreensão da pedagogia como ciência da educação é desconsiderada:

Ligado ao movimento mais geral de reificação da prática pedagógica, sentimos a necessidade de explorar também os caminhos de uma subestimação do próprio pedagógico no trabalho do professor do ensino superior. Por que a tendência, neste nível de ensino que tanto se aproxima do desenvolvimento da ciência, em desconsiderar a própria pedagogia como ciência? Se o trabalho pedagógico é tomado via o empirismo e a imitação de modelos, ou então "intuitivamente", há uma desconsideração para com o aspecto científico deste trabalho (SCHEIBE, 1987, p. 148).

Sendo assim, há, no pensamento hegemônico, uma desconsideração da dimensão científica da docência, como se o trabalho docente fosse uma consequência natural do 
conhecimento geral que possuem os professores (MELO, 2018). O foco para o exercício da docência universitária é no domínio de conteúdos, oriundos dos campos científicos específicos, entretanto, passam à largo da dimensão didático-pedagógica. Almeida (2012) anuncia que a docência universitária é constituída por duas grandes referências que consistem na base de seus fundamentos: o mundo do trabalho e o universo da pesquisa. Esse contexto tem como pressuposto a ideia de que para atuar como professor, basta ter o "domínio" do conteúdo a ser ensinado, a partir da máxima: “quem sabe, sabe ensinar” (MELO, 2009).É comum, também, a falácia do discurso de que se tem o “dom” para ensinar, logo não há necessidade de aprender a profissão, pois se trata de um saber “inato".

Esse contexto, marcado pelas fragilidades formativas, é escamoteado na omissão de políticas públicas de formação específica para o ingresso na carreira do magistério superior. No caso da LDB 9394-96 - Lei de Diretrizes e Bases da Educação, dois artigos mencionam a docência universitária, sendo que o artigo 65 exclui a necessidade de prática de ensino para atuar nesse nível:

Artigo 65 - A formação docente, exceto para a educação superior, incluirá prática de ensino de, no mínimo, trezentas horas.

Artigo 66 - A preparação para o exercício do magistério superior far-se-á em nível de pós-graduação, prioritariamente em programas de mestrado e doutorado (BRASIL, 1996).

Cabe destacar que o termo "preparação" em substituição ao vocábulo "formação" já explicita a concepção escamoteada de atuação profissional do professor universitário. Sendo assim, a preparação é compreendida como uma dimensão mais superficial, composta por conhecimentos que podem ou não responder às demandas profissionais de atuação na docência universitária. O termo formação indica necessidade de maior sistematização, portanto, remete à ideia de profundidade quanto ao necessário domínio científico do campo específico, assim como do campo da educação.

A inserção na docência demanda a construção de atitudes, iniciativas, conceitos e tomadas de decisões, seja em quaisquer níveis de atuação. No tocante ao ensino superior, o cenário tem seus desafios peculiares, sua dinâmica de funcionamento e seus propósitos sociais, ideológicos e políticos. Nesse universo, os atores se encontram em busca da produção do conhecimento. "A docência universitária é profissão que tem por natureza constituir um processo mediador entre sujeitos essencialmente diferentes, professor e alunos, no confronto e na conquista do conhecimento" (PIMENTA e ANASTASIOU 2005, p. 9). 
Na contemporaneidade esses espaços atravessam mudanças velozes, ao tempo em que os processos formativos dos docentes envolvidos nem sempre consegue atender às demandas impostas pelo contexto macrossocial. Na verdade, esse equilíbrio depende, essencialmente, do envolvimento dos profissionais professores no debate sobre a própria formação, diante das condições oferecidas pelas instituições. Para Almeida e Pimenta (2009, p. 22):

[...] as novas demandas postas à formação de futuros profissionais trazem como decorrência a necessidade de se processar uma profunda renovação no contexto da sala de aula e nas metodologias de ensino universitário, o que coloca implicações novas para os docentes em seu trabalho formativo. [...]trata-se, portanto, de propiciar condições formativas para que se desenvolva uma mudança de paradigma orientador desse processo, o que requer reorientação nos objetivos, na metodologia docente, nas estratégias de ensino- aprendizagem, nos sistemas de avaliação, na organização dos recursos e espaços de trabalho. [...] trata-se, portanto da necessidade de constituição de um novo paradigma de docência universitária.

A formação e a docência são atravessadas por uma complexidade de interações, essencialmente importantes, de conhecimentos diversos. Nesse movimento, não há como eleger o domínio dos conhecimentos teóricos como único substrato nutritivo da docência. Aos conhecimentos teóricos serão associados conhecimentos sobre o contex to do trabalho docente, o cenário e os atores e atrizes, as demandas sociais, as determinações legais, os desafios do ser, saber e fazer docentes. Nas palavras de Tardif e Raymond (2000, p. 217$)$, temos que:

Os alunos passam através da formação inicial para o magistério sem modificar substancialmente suas crenças anteriores sobre o ensino. E, tão logo começam a trabalhar como professores, sobretudo no contexto de urgência e de adaptação intensa que vivem quando começam a ensinar, são essas mesmas crenças e maneiras de fazer que reativam para solucionar seus problemas profissionais.

Nesse sentido, a formação para a docência universitária é ampla, de tal modo que demanda investimentos específicos, tanto de políticas quanto de programas formativos, associados às análises das necessidades dos/as próprios/as professores/as diante dos desafios encontrados desde a inserção na carreira docente. As percepções que esses/as profissionais revelam sobre a própria profissão auxiliam na compreensão de conceitos derivados e igualmente relevantes. Nesse sentido,

[...] a formação, encarada do ponto de vista do aprendente, torna-se um conceito gerador em torno do qual vêm agrupar-se, progressivamente, conceitos descritivos: processos, temporalidade, experiência, aprendizagem, conhecimento e saber-fazer, temática, tensão dialética, consciência, 
subjetividade, identidade. Pensar a formação [...] é evidentemente, não ignorar o que dizem as disciplinas das ciências do humano (JOSSO, 2004, p. 38).

A formação de professores é um processo social, histórico, político, filosófico e cultural, logo, multidimensional. Nos estudos de autores como Tardif (2002); Gauthier, (1998); Pimenta, (2000) encontramos apontamentos sobre a multidimensionalidade da docência, com expressiva indicação de que além do conteúdo específico referente às áreas de ensino, cada professor/a há de conquistar diversos outros domínios e saberes.

É no exercício da docência universitária que as necessidades formativas, cerne deste estudo, brotam e se constituem como dimensão a ser considerada como norteadora dos processos de formação e desenvolvimento profissional docente. Além disso, a preocupação com a aprendizagem da profissão deve estar alicerçada na organização de projetos formativos que, ao partirem dos próprios docentes e das questões e dificuldades que emergem de suas práticas pedagógicas, possam colaborar para a formação profissional.

Em face das demandas formativas dos docentes, cabe ressaltar a importância de criar projetos orientados por ações colaborativas e por práticas dialógicas, que se constituam como espaço crítico-reflexivo da profissão docente. E, ainda, que a construção dos conhecimentos profissionais da docência seja oportunizada, por meio de debates teoricamente fundamentos no campo da educação, em que a unidade teoria-prática possa se constituir em possibilidades de uma práxis pedagógica transformadora.

\section{2- Pedagogia Universitária: em foco a defesa pela formação e profissionalização docente}

Embora a pedagogia universitária já se constitua, há pelo menos 20 anos como objeto de pesquisas no Brasil e no exterior, seu reconhecimento como campo científico ainda não está consolidado (MELO, 2018). No prefácio da Enciclopédia de Pedagogia Universitária, a autora Morosini (2006, p. 57) apresenta a seguinte constatação: "critica-se e escreve-se muito sobre Ensino Superior, mas produz-se pouco conhecimento sobre a pedagogia que o sustenta”. A autora referida indica que a pedagogia universitária surge na tradição cultural francesa, com enfoque no "estudo do conhecimento como matéria-prima do ensinaraprender”. A centralidade das discussões é, portanto, no processo de ensino-aprendizagem. Para a autora referida, no contexto latino-americano, “a pedagogia universitária, nucleada 
no campo educativo, opera no espaço transdisciplinar da academia” (MOROSINI, 2006, p. $57)$.

Conforme indica Morosini (2006, p. 57) a pedagogia universitária "tem como objeto de estudo o ensino, a aprendizagem e a avaliação na universidade. Preocupa-se com a formação docente para o exercício pedagógico profissional”. Sendo assim, constitui-se por meio de reflexões e proposições frente aos desafios atinentes ao contexto universitário. Contexto esse marcado, cada vez mais, pela diversidade de concepções e de práticas, pelas constantes oscilações quanto ao sentido formativo da universidade, pelas pressões de políticas pautadas no ideário neoliberal e, ainda, pela inexistência de políticas institucionais de formação e desenvolvimento profissional docente.

A complexidade da pedagogia universitária se constitui, na medida em que esse nível da educação ocorre em uma instituição social que tem compromissos com o desenvolvimento humano. Entretanto, nem sempre cumpre suas finalidades formativas, uma vez que se ocupa, principalmente, com a formação profissional de seus estudantes e, não raro esse processo encontra-se distanciado da construção do pensamento crítico e criativo, ético e estético, inerentes à perspectiva emancipatória.

Para Melo (2018, p. 45) “[ [...] essa formação ocorre por meio de atividades e finalidades diversificadas, é orientada por intencionalidades e racionalidades diferentes, balizadoras das relações professor-estudante, ensino-aprendizagem, conteúdo-forma”. Sendo assim, é comum que os princípios formativos preconizados pelas instituições não sejam considerados no planejamento e desenvolvimento dos processos formativos. Um dos desafios políticopedagógicos está sintetizado na compreensão de que há:

Redes e teias de conhecimentos que trazem o universal para o singular da sala de aula e levam as expressões de subjetividades individuais ao universo global das coletividades, ampliando as densidades emancipatórias de processos de interação humana (MOROSINI, 2006, p. 58).

Cada vez mais, as universidades têm sido convocadas a responderem por questões e problemas sociais, que se apresentam como dilemas em seu cotidiano. Dentre os principais impasses destacamos o desinteresse dos estudantes, problemas relacionados ao alcoolismo, uso de drogas ilícitas, depressão, evasão, dentre outros. Nesse sentido,

O que fica evidente, entretanto, é a emergência de saberes que antes eram desconsiderados para os profissionais da universidade, exigindo o fortalecimento do campo da pedagogia universitária. Os tradicionais desempenhos não mais dão conta das condições concretas das práticas 
acadêmicas. Não basta um professor erudito para provocar aprendizagem nos alunos; é preciso entender as múltiplas demandas para esse profissional e reconhecer a docência universitária como uma ação complexa (CUNHA, 2014, p. 12 - grifos meus).

Diante dessas questões, é possível afirmar que grande parte dos desafios para o cumprimento das finalidades da educação superior relaciona-se, diretamente, à tríade professor-estudante-conhecimento. No contexto de uma pedagogia universitária cabe questionar: como desenvolver processos formativos que, de fato, contribuam para o desenvolvimento humano, intelectual, cultural e profissional dos estudantes? Quais saberes devem possuir os docentes para concretizarem seus objetivos formativos? A defesa que faço é por uma educação superior que seja norteada por valores humanistas e democráticos. Para tanto, o professor será um “intelectual transformador”, conforme proposto por Giroux (1997, p. 163). Será a partir dessa identidade que o professor poderá “ajudar os estudantes a desenvolverem uma fé profunda e duradoura na luta para superar injustiças econômicas, políticas e sociais, e humanizarem-se ainda mais como parte desta luta”. Essa proposição implica,de acordo com Giroux (1997, p. 163), em “tornar o pedagógico mais político e o político mais pedagógico”, no contexto formativo da pedagogia universitária.

A docência, como profissão é atividade complexa, que tem por natureza, conforme indicam Pimenta e Anastasiou (2005), "constituir um processo mediador entre sujeitos essencialmente diferentes, professor e alunos, no confronto e na conquista do conhecimento". A concretização dos processos de ensino-aprendizagem representa a essencialidade do trabalho docente, que situado e datado em um tempo determinado, é denominado de aula. A aula, que pode ser realizada em diversos locais, é considerada como o espaço privilegiado para a reconstrução dos saberes docentes e discentes, para as interações necessárias entre sujeitos e objetos a serem conhecidos.

Ao defendermos que a docência se compõe de saberes específicos e pedagógicos, é indiscutível que haja a defesa por processos formativos que viabilizem a sólida formação teórica no campo específico, assim como a densidade de conhecimentos relacionados à dimensão pedagógica. Os saberes docentes estão diretamente vinculados à concepção de identidade profissional e, por conseguinte, ao desenvolvimento profissional. As diversas formas de como os saberes são mobilizados e construídos no cotidiano acadêmicos são relevantes e devem ser consideradas como balizadoras dos processos formativos, pois é por meio deles que os professores se identificam com a profissão docente. Diante desse posicionamento, Behrens reafirma que: 
A formação continuada exige a elaboração de propostas alicerçadas com base nas necessidades dos docentes, com intuito de gerar a mudança desejada na prática pedagógica. Para tanto, as propostas para formação do profissional docente são construídas com eles, e não para eles (BEHRENS, 2007 p. 450).

Essa perspectiva indica considerar os professores como protagonistas de seus processos formativos, na medida em que suas necessidades formativas e interesses profissionais devem se constituir em eixo central da formação. Coêlho (2009, p. 204-205) nos faz a seguinte provocação: “interrogar a educação é perguntar qual o sentido e a finalidade da existência coletiva e individual, das obras de cultura, em sua complexidade, historicidade, contradições e ambiguidades, em seu fazer-se ao mesmo tempo múltiplo e inseparável do Uno”. Nesse sentido,

A formação é um processo que se constitui dialeticamente, por meio de embates e tensões contraditórias entre as dimensões individual e coletiva; entre perspectivas e intencionalidades: formar para a alienação ou emancipação. Pela própria natureza que subjaz às questões éticas e políticas, é possível afirmar que as práticas formativas são indissociáveis dos resultados que produzem (MELO, 2018, p. 53).

Sendo assim, não há outro caminho para organizar os processos formativos senão aquele que tenha as necessidades formativas como ponto de partida e de chegada, em uma perspectiva crítico-dialética. A categoria "necessidades formativas" tem se constituído, no campo de formação e professores do magistério superior, como essencial. Ao aprofundar a compreensão a respeito das necessidades formativas de professores é possível contribuir para a consolidação de políticas de formação que reverberem na qualidade do trabalho pedagógico realizado nesse nível de ensino. Políticas de formação, que, de fato, assegurem processos formativos permanentes, que tenha sua gênese no envolvimento dos docentes, a partir de seus interesses e necessidades formativas, como balizadores da formação em contexto.

Para Rodrigues (1991, p. 476), a necessidade é "resultante do confronto entre expectativas, desejos e aspirações, por um lado e, por outro, as dificuldades e problemas sentidos no quotidiano profissional”. Sendo assim, qualquer projeto de formação deve estar intrinsecamente vinculado às demandas em contexto, onde se produz a docência. É, portanto, nesse contexto da docência universitária, que os docentes experienciam e produzem, constantemente, as necessidades formativas. Ao serem consideradas como norteadoras dos projetos de formação, poderão se constituir em investimento na formação pedagógica permanente, que seja articuladora das práticas e experiências às teorias educacionais, mediadas por metodologias que considerem tais necessidades, bem como o trabalho coletivo e a valorização da carreira. 
Rodrigues e Esteves (1993, p.13), indicam que o termo "necessidade" remete, necessariamente, a um juízo de valor, pois: “[ [..] necessidade implica sempre, mais ou menos, diretamente, algum problema de valor ou de referência, ou certas normas sociais em função das quais se mede a necessidade”. É no decorrer de sua atuação profissional e diante dos inúmeros enfrentamentos que a prática pedagógica oferece, que o docente universitário começa a perceber suas necessidades formativas. De maneira geral, uma necessidade formativa pode ser, de acordo com Zabalza (1998, p. 62):"Instituída pela discrepância que se produz entre a forma como as coisas deveriam ser (exigências), poderiam ser (necessidades de desenvolvimento) ou gostaríamos que fossem (necessidades individualizadas) e a forma como essas coisas são de fato”, portanto, torna-se necessário considerar e articular essas dimensões, para que a formação, de fato seja significativa, pois os processos formativos demandam adesão e consentimento dos professores, caso contrário, não promovem mudanças.

Cabe às instituições de ensino superior a criação e institucionalização de políticas de desenvolvimento profissional de seus professores que tenham as necessidades formativas como ponto de partida para a formação. Essa preocupação precisa permear a formação docente desde a inicialização da carreira profissional e permanecer em “[...] um contínuo processo de desenvolvimento profissional dos docentes" (VAILLANT; MARCELO, 2012, p. 125), com especial dedicação ao atendimento das demandas de sua atuação, compondo “[ [...] as primeiras experiências de trabalho como fundantes dos saberes que constroem” (CUNHA, 2005, p. 89).O início da carreira docente carrega consigo marcas fundamentais para análises das necessidades formativas. Do ponto de vista de Cunha (2009, p. 17) as marcas do início da carreira geralmente são “[...] desiguais, complexas e instáveis [...]”, portanto, é imprescindível o conhecimento e a interpretação sensível das particularidades, pois será a partir delas que projetos formativos podem ser elaborados e contribuírem para o desenvolvimento profissional docente.

O cenário da docência universitária em estudo tem particular relevância, uma vez que o universo de professores/as tem relações distintas com o contexto local, transitam entre cidades diferentes, constituem relações pessoais e profissionais inseridas em dinâmicas particulares, tiverem formações em instituições distintas, e atuam no atendimento de alunos/as oriundos de contextos sociais peculiares. É notória a necessidade de adaptação por parte desses/as profissionais, assim como aponta Garcia (2006) para quem, o amoldamento diante do panorama sociocultural, pode ser potencializado quando há aproximação entre as experiências vividas no âmbito pessoal com os desafios postos pela carreira docente. 
A docência universitária assume-se em complexidades. São nuanças múltiplas que se completam, mantem relações e interações primordiais ao desenvolvimento profissional. Nesse sentido, Tancredi (2009) indica que essa complexidade exige dos/as profissionais mais empenho e envolvimento com seus processos formativos, ao mesmo tempo em que precisa enfrentar as situações de desvalorização social da carreira e da profissão.

As necessidades formativas, conforme indicam Benedito, Imbernón e Félez (2001, p. 3) possuem caráter polissêmico. Assim:

Necessidade é tanto o conjunto de aspectos considerados inerentes ao desenvolvimento dos professores novos sem o qual se pode afirmar que possuem uma carência formativa, como o que o professorado manifesta como necessário e do qual deseja obter uma capacitação para poder realizá-lo.

Os referidos autores indicam que as necessidades, tanto de professores iniciantes, quanto professores mais experientes podem apresentar carências e desejo em participar de ações formativas. O termo "capacitação" utilizado pelos autores remete a ideia de treinamento, portanto, está relacionado a concepções conservadoras de formação. Sobre esse aspecto, Melo enfatiza que,

As concepções de formação de professores, antes a partir da ótica da capacitação, ou seja, da transmissão pura e simplesmente de conhecimentos prontos, para que os professores estivessem "treinados" para o exercício da docência, têm dado lugar a uma outra abordagem: a análise das práticas docentes, enfatizando os saberes dos professores, como estes são mobilizados e construídos no cotidiano acadêmico (MELO, 2009, p. 32).

Diante do exposto, destacamos a importância do contexto, cenário da atuação docente, como essencial para construir compreensões sobre as fragilidades da formação docente, que se traduzem em necessidades formativas. Nas palavras de Marcelo Garcia, (2006) no contexto de seu trabalho, os professores/as constroem a própria profissionalidade, ensinando e aprendendo a ensinar. Esse movimento torna-se uma necessidade formativa, sobretudo porque os cenários e os sujeitos sociais envolvidos neles e com eles são dinamicamente modificados. No entanto, cabe destacar que a docência é comumente exercida a partir de modelos que foram construídos no decorrer de toda a trajetória formativa e profissional dos professores. Ou seja, os docentes ensinam como foram ensinados/as, reproduzindo e perpetuando práticas de ensino mais ou menos eficientes, em uma transmissão mais ou menos eficaz de saberes. (CORTESÃO apud CUNHA, 2005). 


\section{Conclusões}

O presente artigo teve como objetivos apresentar reflexões sobre a necessidade e importância de formação docente para atuar na educação superior. O estudo da literatura evidencia que os problemas e dilemas enfrentados pelos docentes universitários são históricos e estão relacionados à cultura de que o domínio do conteúdo específico seja o bastante para assegurar ao docente a atividade profissional de ensinar. Entretanto, frente à complexidade da realidade multidimensional, tecnológica e digital, os estudantes apresentam demandas que se traduzem em grandes desafios para o professor, principalmente, para aqueles que ainda desenvolvem a docência a partir de práticas pedagógicas conservadoras. A análise evidencia a essencialidade de construir projetos institucionais que tenham como ponto de partida as necessidades formativas dos professores em contexto e, que reconheçam na pedagogia universitária o espaço profícuo para formação e profissionalização docente.

\section{Referências}

ALMEIDA, Maria Isabel de. Formação do professor do ensino superior. Desafios e políticas institucionais. São Paulo: Cortez, 2012.

ALMEIDA, Maria Isabel de \& PIMENTA, Selma Garrido. Pedagogia Universitária: valorizando o ensino e a docência na Universidade de São Paulo. In: PIMENTA, Selma Garrido \& ALMEIDA, Maria Isabel de (orgs.). Pedagogia Universitária. São Paulo: EDUSP, 2009, p. 13-38.

BENEDITO, Vicente; IMBERNÓN, Francisco.; FÉLEZ, Beatriz. Necesidades y propuestas de formación del profesorado novel de la Universidad de Barcelona. Profesorado: Revista de Currículum y Formación del Profesorado, Espanha, v. 5, n. 2, p. 75-102, 2001.

BEHRENS, M. O paradigma da complexidade na formação e no desenvolvimento profissional de professores universitários. In: Educação. Porto Alegre. N. 3. 2007.

BOLZAN, D. P. V; ISAIA, S. M. A. Pedagogia Universitária e Aprendizagem Docente: relações e novos sentidos da professoralidade. In: Diálogo Educacional, Curitiba, v. 10, n. 29, p. 13-26, jan./abr. 2010. Disponível em https://periodicos.pucpr.br/index.php/dialogoeducacional/article/viewFile/3043/2971.

BRASIL. Lei n. 9.394 de 20 de dezembro de 1996. Lei de Diretrizes e Bases da Educação Nacional. Diário Oficial da União, Brasília, DF, 23 dez. 1966.

COÊLHO, I. M. Escola e formação de professores. In: COÊLHO, I. (Org.). Educação, cultura e formação: o olhar da filosofia. Goiânia: Ed. PUC Goiás, 2009. 
CORRÊA, Guilherme Torres; RIBEIRO, Victória Maria Brant. A formação pedagógica no ensino superior e o papel da pós-graduação stricto sensu. Educ. Pesqui., São Paulo, v. 39, n. 2, p. 319-334, abr./jun. 2013.

CUNHA, M. I. A Docência como ação complexa: o papel da Didática na formação de professores. In: ROMANOVISKI, J.; MARTINS, P. L. O.; JUNQUEIRA, S. R. A. (Orgs.) Conhecimento Local e Conhecimento Universal: pesquisa, didática e ação docente. Curitiba/PR: Champagnat, 2004. p. 31-42.

CUNHA, Maria Isabel da et. al. Políticas Públicas e docência na Universidade: novas configurações e possíveis alternativas. In: CUNHA, Maria Isabel da (org). Formatos Avaliativos e Concepções de Docência. Campinas: Autores Associados, 2005, p. 69-91.

CUNHA, Maria Isabel da. Trajetória e lugares da formação do docente da educação superior: do compromisso individual à responsabilidade institucional. In: REUNIÃO ANUAL DA ANPED, 2009, Caxambu. Anais... Caxambu/MG: ANPED, 2009. p. 1-13. Disponível em. Acesso em: 1 set. 2016.

CUNHA, Maria Isabel da. A qualidade e ensino de graduação e o complexo exercício de propor indicadores: é possível obter avanços? Avaliação, Campinas; Sorocaba, SP, v. 19, n. 2, p. 453462 , jul. 2014.

GAUTHIER, C. Por uma teoria da Pedagogia: pesquisas contemporâneas sobre o saber docente. Ijuí: Unijuí, 1998.

GIROUX, H. A. Os Professores como Intelectuais. Porto Alegre: Artmed Editora, 1997.

GIROUX, H. A. Pedagogia crítica como projeto de profecia exemplar: cultura e política no novo milênio. In: IMBERNÓN, F. A Educação no Século XXI. Os desafios do futuro imediato. Trad. Ernani Rosa. 2.ed. Porto Alegre: ArtMed, 2000. p. 120-138.

JOSSO, M. C. Experiências de vida e formação. São Paulo, Cortez, 2004.

MARCELO, C. G. Políticas de inserción a ladocencia: Del eslabón perdido al puente para eldesarrolloprofesional docente. Documento elaborado para o Taller Internacional "Las políticas de inserción de losnuevos maestros enlaprofesión docente: La experiencia latinoamericana y el caso colombiano". Colombia, Bogotá, 2006. Disponível em: $<$ http://www.ub.edu/obipd/docs/politicas_de_insercion_a_la_docencia_del_

eslabonperdido_al_puente_para_el_desarrollo_profesional_docente_garcia_c_m.pdf >.

MARCELO GARCIA, C. Desenvolvimento Profissional: passado e futuro. Sísifo - Revista das Ciências da Educação, n. 08, p. 7-22, jan./abr. 2009.

MELO, G. F. Tornar-se Professor: a formação desenvolvida nos cursos de Física, Matemática e Química da Universidade Federal de Uberlândia. 2007. 233f. Tese (Programa de PósGraduação em Educação) - Faculdade de Educação, Universidade Federal de Goiás, Goiânia, 2007. 
MELO, G. F. Docência: uma construção a partir de múltiplos condicionantes. Boletim Técnico do SENAC: a revista da educação profissional, Rio de Janeiro, v. 35, n.1, p. 29-37, janeiro/abril 2009.

MELO, G. F. Pedagogia Universitária: aprender a profissão, profissionalizar a docência. Curitiba: CRV, 2018.

MOROSINI, M. C.. (Editora-Chefe). Enciclopédia de Pedagogia Universitária-Glossário Vol.2. Brasilia: INEP/RIES, 2006.

PIMENTA, S. G. (Org.). Pedagogia, ciência da educação? São Paulo: Cortez, 1996.

PIMENTA, S. G. (org.). Saberes pedagógicos e atividade docente. 2. ed. São Paulo: Cortez, 2000.

PIMENTA, Selma Garrido \& ANASTASIOU, Léia. Docência no ensino superior.São Paulo: Cortez, 2002.

PIMEntA, S. G.; ANASTASiOU, L. G. C. Docência no Ensino Superior. 2.ed. São Paulo: Cortez, 2005.

PIMENTA, S. G.; ALMEIDA, M. I. Pedagogia Universitária: caminhos para a formação de professores. São Paulo: Cortez Editora, 2011.

RODRIGUES, M. A. Necessidades de Formação: contributo para o estudo das necessidades de formação dos professores do ensino secundário. Universidade de Lisboa, Lisboa, 1991.

RODRIGUES, M A. ; ESTEVES, M. A análise de necessidades formativas na formação de professores. Portugal: Porto editora, 1993.

SCHEIBE, Leda. Pedagogia universitária e transformação social. Tese (Doutorado em Educação) - Faculdade d eEducação, Pontifícia Universidade Católica de São Paulo, São Paulo, 1987.

TANCREDI, Regina, Maria Simões Puccinelli. Aprendizagem da docência e profissionalização: elemento de uma reflexão. São Carlos: EdUFSCar, 2009. Coleção UAB-UFSCar. 62 p.

TARDIF, M. Saberes docentes e formação profissional. 2. ed. Petrópolis: Vozes, 2002.

TARDIF, Maurice e RAYMOND, Danielle. Saberes, tempo e aprendizagem do trabalho no magistério. Educação e Sociedade. Campinas: UNICAMP, ano XXI, n ${ }^{\circ}$ 73, dez, 2000. Disponível em: http://www.scielo.br/pdf/es/v21n73/4214.pdf.

VAILLANT, D.; MARCELO, C. Ensinando a ensinar: as quatro etapas de uma aprendizagem. Curitiba: UTFPR, 2012.

ZABALZA, M. A. Planificação e desenvolvimento curricular na escola. Lisboa: edições ASA, 1998. 